\title{
Association between symptoms and severity of disease in hospitalised novel coronavirus (COVID-19) patients: A systemic review and meta-analysis
}

Ashis Talukder ( $\square$ ashistalukder3168@ku.ac.bd)

Khulna University

Shaharior Rahman Razu

Khulna University

Sheikh Alif

Monash University

Muhammad Aziz Rahman

Federation University

Sheikh Mohammed Shariful Islam

Deakin University

\section{Research Article}

Keywords: Coronavirus, COVID-19, symptoms, respiratory, severity

DOI: https://doi.org/10.21203/rs.3.rs-31795/v1

License: (c) (1) This work is licensed under a Creative Commons Attribution 4.0 International License. Read Full License 


\section{Abstract}

Background Symptoms of the novel coronavirus disease (COVD-19) are well known, although asymptomatic cases were also reported due to this rapidly evolving viral disease. However, there has been limited research with inconsistent findings on symptoms of COVID-19 and diseases severity. We aimed to evaluate the association between symptoms and severity of disease in confirmed COVID-19 cases by performing a meta-analysis.

Methods We conducted a systematic review by searching four online databases (Medline, Web of Science, EMBASE and Cochrane library) of published studies that included symptoms of COVID-19 cases and severity of the disease between 01-Jan-2020 and 20-Apr-2020. PRISMA and MOOSE guidelines were followed, and only articles published in English were selected. We performed meta-analysis using Mantel-Haenszel random-effects model. Degree of heterogeneity among studies and quality of the selected studies were evaluated.

Results Out of 153 articles identified, a total of seven articles, including 3,168 participants, met the inclusion criteria and were included. The median age of the patients was 49 years, 1818 (57.38\%) were males, and 574 (18.11\%) reported severe conditions. Fever was the most commonly reported symptom in the reported COVID-19 confirmed cases (87.89\%, 95\% Cl: 83.22-81.39\%), which was followed by cough, myalgia or fatigue, and less proportionally dyspnea and headache. Dyspnea was the only symptom, which was associated with severity of COVID-19 (OR 2.38, 95\% Cl: 1.83-3.10).

Conclusions Dyspnoea was found to be associated with severity of COVID-19. People with existing respiratory illnesses, such as chronic obstructive pulmonary diseases need to be careful about the onset of such symptom and should seek medical attention.

\section{Background}

The novel coronavirus disease 19 (COVID-19) is a pathogenic viral infection caused by severe acute respiratory syndrome coronavirus 2 (SARS-CoV-2). The condition has received enormous worldwide attention due to its high human-to-human transmissibility following the first cases reported in Wuhan, China, in December 2019 [1, 2]. COVID-19 belongs to the same subgroup of coronavirus diseases. However, it is homologically far different from its predecessors like severe acute respiratory syndrome coronavirus (SARS-CoV) and Middle East respiratory syndrome coronavirus (MERS-CoV) [3]. Although the disease is mild in most people, it may progress to severe illness like pneumonia, acute respiratory distress syndrome (ARDS) and multi-organ dysfunction causing a fatality.

The clinical spectrum of COVID-19 varies from asymptomatic or presenting few symptoms to symptomatic forms as the first symptoms usually appear after five to six days, according to the World Health Organization (WHO) reports [4]. Common symptoms include fever, fatigue, dry cough, sore throat and dyspnea while pneumonia, sneezing, malaise, diarrhea, headache and Conjunctivitis [5-9], loss of taste and smell [10] have also been reported. Due to its typical progressive and aggravation process, COVID-19 has been classified from mild to severe types based on the severity of the disease by the Beijing Centers for Diseases Control and Prevention (NHC China, 2020) [10]. Globally, $80 \%$ of the reported COVID-19 cases presented with mild respiratory symptoms, $15 \%$ of cases required hospitalisation and $5 \%$ cases were critical in nature [12]. Previous studies have reported the severity of COVID-19 cases, but results were inconsistent [11-14]. Several systematic reviews have reported COVID-19 symptoms and comorbidities [15-17], but none have explored the associations of COVID-19 symptoms with the severity of the disease. Therefore, we aimed to perform a systematic review and meta-analyses of COVID-19 symptoms associated with severity of the disease. Results will help to understand associations of symptoms with 
disease severity, develop patient appropriate strategies and interventions, including policy measures to improve COVID-19 management in coming days.

\section{Materials And Methods}

\section{Search strategy and selection criteria}

This systematic review and meta-analysis were conducted according to PRISMA and MOOSE guidelines [18, 19]. An extensive search strategy was designed to retrieved all published articles from January 1, 2019, to April 20, 2020, in PubMed (Medline), Web of Science, EMBASE, and Cochrane Library databases. Search results were compiled using the bibliographic software Endnote ${ }^{\mathrm{TM}} \mathrm{X9.2}$. Based on the criteria of different databases, we used the following search terms: '2019-nCoV', or '2019 novel coronavirus', or 'COVID-19', or 'clinical characteristics of COVID-19' or 'symptoms of coronavirus'. We additionally screened the list of references for each selected article to identify studies that may have been missed during the initial search. Two independent researchers (AT and SRR) screened retrieved articles. The same investigators independently assessed full texts of records deemed eligible for inclusion. Any discrepancies were resolved by discussion and consensus with a senior investigator (SMSI).

We included peer-reviewed studies published in the English language that reported the clinical characteristics of COVID-19, particularly the symptoms of novel coronavirus patients with their prevalence and distribution of patients based on the severity of the disease. All the included studies patients were hospitalised cases of COVID-19, confirmed by the laboratory-based Real-Time Reverse Transcription Polymerase Chain Reaction Assay (RT-PCR). We excluded studies that focused in children and did not reported the clinical diagnostic criteria along with duplicate publications, single case reports, reviews, editorials, letters or (c) studies provide insufficient information on the relevant topic.

\section{Data extraction and variables}

Two authors (AT and SRR), who involved in the literature screening, also extracted the data independently from the selected studies. Differences were settled by conversation or a third analyst (SMSI). We obtained the following variables: first author, year of publication, number of patients, age, sex, number of severe and non-severe patients, and the prevalence of several symptoms including fever, cough, myalgia or fatigue, dyspnea and headache. "Patients with any of the following features at the time of, or after, admission was classified as severe cases: (1) respiratory distress ( $\geq 30$ breaths per $\mathrm{min}$ ); (2) oxygen saturation at rest $\leq 93 \%$; (3) ratio of the partial pressure of arterial oxygen to the fractional concentration of oxygen inspired air $\leq 300 \mathrm{~mm} \mathrm{Hg}$; or (4) severe disease complications (e.g., respiratory failure, the requirement of mechanical ventilation, septic shock, or non-respiratory organ failure) [11]."

\section{Data analyses}

All analyses were performed by $\mathrm{R}$ software (version 3.6.1). The odds ratios (OR) was considered to describe the severity of clinical symptoms in severe patients compared to non-severe patients. Due to the presence of heterogeneity in studies, Mantel-Haenszel random-effect models were utilised to estimate the average effect along with its precision, which can provide a more reliable estimate of the $95 \%$ confidence intervals (Cl). To assess heterogeneity, we used the statistic and Cochran's Q test.

\section{Study quality and publication bias}


We used The Newcastle-Ottawa Scale (NOS) for assessing the quality of studies in meta-analysis [20]. The NOS summarised 8 aspects of each study: case definition adequacy, representativeness of the cases, selection of controls, the definition of controls, comparability of cases and controls on the basis of the design or analysis, ascertainment of exposure, the same method of ascertainment for cases and controls, and comparison of nonresponse rate between cases and controls. Studies with a score 6 or more out of 9 total points were considered as high-quality studies. We used funnel plot and Egger's test to assess the publication bias.

\section{Ethical Approval}

This study need no ethical approval since our study used published article for data collection.

\section{Results}

The search produced 153 articles. Out of these, we excluded 71 duplicate articles. After a screening of the title and abstract, 52 articles were excluded. Finally, we reviewed the full text and removed 23 articles since they were reviews, case reports, editorials and had lack of information. Seven articles [6, 8, 21-25] including 3168 COVID-19 patients eventually met the inclusion criteria and were included. All the included studies were hospital-based crosssectional and conducted in Wuhan or mainland China. The flow diagram of the literature search was shown in Figure 1.

The median age of the patients was 49 years, and 1818 (57.38\%) were males (Table 1). Among these patients, there were 574 (18.11\%) in severe condition (Table 1). Fever (87.89\%, 95\% Cl: 83.22-81.39\%) was the most prevalent symptoms observed in COVID-19 patients, followed by cough (68.23\%, 95\% Cl: $63.52-70.74 \%)$, myalgia or fatigue (45.04\%, 95\% Cl: 32.29-55.18\%), dyspnea (27.03\%, 95\% Cl: $21.52-33.34 \%)$ and headache (13.08\%, 95\% Cl: 9.52-17.72\%). The prevalence was estimated from random effect model and significant () heterogeneities were observed for the estimates with ranging from $62 \%$ to $95 \%$ (see Figure 2).

We found that all studies reported the presence of pneumonia and abnormal chest imaging in most of the patients on admission. Four studies reported that ground-glass opacity was the most common feature on chest computed tomography (CT), which was followed by bilateral patchy shadowing $[6,8,21,23]$. The findings from the CT was almost similar to the CXR as reported by the studies. The most prevalent comorbidities were hypertension and diabetes [22] which are followed by acute respiratory distress syndrome (ARDS) $[6,8,21]$ and among them, a large proportion of patients worsened in a shorter period of time and developed multi-organ disorder.

Figure 3 shows the meta-analysis of the association between symptoms with severe and non-severe patients. Higher odds of dyspnea (OR 2.38, 95\% Cl: 1.83-3.10) was observed in the severe group. The odds of fever (OR 1.06, 95\% Cl: 0.88- 1.28), cough (OR 1.11, 95\% Cl: 0.91- 1.36), myalgia or fatigue (OR 1.11, 95\% Cl: 0.88- 1.40), and headache (OR 1.02, 95\% Cl: 0.68-1.54) were also found higher in the severe COVID-19 patients. However, except dyspnea, our meta-analysis did not find any statistically significant association with the severity of the disease.

\section{Study quality and publication bias}

All studies included for the meta-analysis were ranked as high-quality studies (Supplementary Table 1). The publication bias was examined for the following symptoms: fever, cough, myalgia or fatigue, dyspnea and 
headache. Figure 4 shows the results of possible publication bias, which were assessed by funnel plots and Egger's test. The results of the Egger's test (all) suggest that there exist no significant publication bias.

\section{Discussion}

This systematic review and meta-analysis provide a recent summary of findings of the association between COVID19 symptoms and its association with disease severity. Our findings suggest patients with dyspnea had more than twice the odds of having a severe COVID-19 illness at the time of hospital admission. This indicates that that the COVID-19 patient with dyspnea having more than double chance of becoming a severe patient. However, we did not find a significant association between fever, cough, myalgia or fatigue and headache with the severity of symptoms, which is contradictory to the previous systematic review and meta-analysis $[26,27]$. The main reason for this difference could be the stricter inclusion criteria in our study that limits the inclusion of some low-powered case-series studies. Furthermore, previous studies only analysed the prevalence of symptoms, while we metaanalysed and presented the Mantel-Haenszel $(\mathrm{MH})$ odds ratio of the severity of symptoms, which is the first time since the outbreak occurred.

Our meta-analysis found that fever is the predominantly reported clinical manifestation in COVID-19 confirmed cases. This was followed by cough, myalgia or fatigue and less proportionally dyspnea and headache. Furthermore, we identified that most of the included studies were limited to middle-aged to older adults, and commonly included male. Our finding is consistent with previous systematic review and meta-analysis that reported significantly higher prevalence of fever and less commonly cough, fatigue and headache (all p $<0.05$ [26, 27]. The prevalence of fever was $92 \%$ (95\% Cl: 89.4-96.2) [27] and 83.3\% (95 Cl: 78.4-87.7) [26], while we found fever in $87.89 \%$ (95\% Cl: 83.22-81.39\%). However, we only included adults, while the previous studies also included children. The frequency of fever in COVID-19 patients on admission is similar in SARS and MERS outbreak, but the prevalence of cough is higher in SARS and COVID-19, compared to MERS $[28,29]$.

Despite a comprehensive analysis, several limitations should be taken into consideration in our study. Firstly, we only included studies from the Wuhan, which limits the number of studies, as well as clinical and demographic characteristics of patients, may be different from other parts of the world, in particular, we were unable to include clinical studies from Europe and America. This also limits the geographical and ethnic differences were not excluded. Secondly, in the pooled analysis, the varying treatment pattern from the hospitals could not be identified, that could vary greatly. Finally, substantial heterogeneities were predominantly observed in several parameters in the meta-analysis given the variation of patient recruitment, intervention technique and treatment provided.

\section{Conclusion}

Our review suggests that dyspnoea is associated with the severity of COVID-19. Therefore, besides the new onset of such symptom, people with existing respiratory illnesses, such as chronic obstructive pulmonary diseases, need to be careful about the onset of such symptom and should seek medical attention early.

\section{Declarations}

\section{Author contributions}

AT, SRR and SMSI were involved in the concept, design, and development of the study and the instruments. AT and SRR screened articles, extracted data, AT performed meta-analysis. All authors participated in drafting the article 
and reviewed the manuscript. All authors read and approved the final manuscript.

\section{Funding}

No fund has been received for conducting this research.

\section{Acknowledgements}

SMSI is funded by a senior research fellowship from the Institute for Physical Activity and Nutrition (IPAN), Deakin University and a post-doctorate fellowship from the National Heart Foundation of Australia and received a career transition grant from the High Blood Pressure Research Council of Australia.

\section{Declaration of Competing Interest}

The authors declare that they have no known competing interests.

\section{References}

1. Shereen MA, Khan S, Kazmi A et al. COVID-19 infection: Origin, transmission, and characteristics of human coronaviruses. J Adv Res. 2020. 24: p. 91-98.

2. Wu JT, Leung K, and Leung GM. Nowcasting and forecasting the potential domestic and international spread of the 2019-nCoV outbreak originating in Wuhan, China: a modelling study. Lancet, 2020. 395(10225): p. 689697.

3. Lu R., Zhao X, Li J et al., Genomic characterisation and epidemiology of 2019 novel coronavirus: implications for virus origins and receptor binding. Lancet, 2020. 395(10224): p. 565-574.

4. Li Q, Guan X, Wu P et al. Early Transmission Dynamics in Wuhan, China, of Novel Coronavirus-Infected Pneumonia. N Engl J Med, 2020. 382(13): p. 1199-1207.

5. Abd El-Aziz, TM. \& Stockand JD. Recent progress and challenges in drug development against COVID-19 coronavirus (SARS-CoV-2) - an update on the status. Infect Genet Evol, 2020. 83: p. 104327.

6. Huang C, Wang Y, Li X, et al., Clinical features of patients infected with 2019 novel coronavirus in Wuhan, China. Lancet, 2020. 395(10223): p. 497-506.

7. Singhal, T, A Review of Coronavirus Disease-2019 (COVID-19). Indian J Pediatr, 2020. 87(4): p. 281-286.

8. Wang D, Hu B, Hu C, et al. Clinical Characteristics of 138 Hospitalized Patients With 2019 Novel CoronavirusInfected Pneumonia in Wuhan, China. JAMA, 2020. 323(11): p. 1061-9.

9. Yang Y, Lu QB, Liu MJ et al., Epidemiological and clinical features of the 2019 novel coronavirus outbreak in China. MedRxiv, 2020.

10. Xiao Y \& Torok ME. Taking the right measures to control COVID-19. The Lancet Infectious Diseases, 2020. 20(5): p. 523-524.

11. Liu Y, Yan LM, Wan L, et al., Viral dynamics in mild and severe cases of COVID-19. The Lancet Infectious Diseases, 2020.

12. COVID, C. and R. Team, Severe outcomes among patients with coronavirus disease 2019 (COVID-19)-United States, February 12-March 16, 2020. MMWR Morb Mortal Wkly Rep, 2020. 69(12): p. 343-346.

13. Wu JT, Leung K, Bushman M, et al., Estimating clinical severity of COVID-19 from the transmission dynamics in Wuhan, China. Nature Medicine, 2020: p. 1-5. 
14. Lai CC, Shih TP, Ko WC, et al., Severe acute respiratory syndrome coronavirus 2 (SARS-CoV-2) and corona virus disease-2019 (COVID-19): the epidemic and the challenges. International journal of antimicrobial agents, 2020: p. 105924.

15. Yang J, Zheng Y, Gou X, et al., Prevalence of comorbidities in the novel Wuhan coronavirus (COVID-19) infection: a systematic review and meta-analysis. International Journal of Infectious Diseases, 2020. 94: p. 9195.

16. Wang T, Du Z, Zhu F, et al., Comorbidities and multi-organ injuries in the treatment of COVID-19. The Lancet, 2020. 395(10228): p. e52.

17. Wang B, Li R, Lu Z, Huang Y. Does comorbidity increase the risk of patients with COVID-19: evidence from meta-analysis. Aging (Albany NY), 2020. 12(7): p. 6049.

18. Moher D, Liberati A, Tetzlaff J, et al., Preferred reporting items for systematic reviews and meta-analyses: The PRISMA statement. PLoS Medicine, 2009. 6(7): p. 1-6.

19. Stroup DF, Berlin JA, Morton SC, et al., Meta-analysis of observational studies in epidemiology: a proposal for reporting. Meta-analysis Of Observational Studies in Epidemiology (MOOSE) group. JAMA, 2000. 283(15): p. 2008-12.

20. Wells GA, Shea B, O'Connell D, et al., The Newcastle-Ottawa scale (NOS) for assessing the quality of nonrandomised studies in meta-analyses. Ottawa: Ottawa Hospital Research Institute, 2011.

21. Chen N, Zhou M, Dong X, et al., Epidemiological and clinical characteristics of 99 cases of 2019 novel coronavirus pneumonia in Wuhan, China: a descriptive study. Lancet, 2020. 395(10223): p. 507-513.

22. Guan WJ, Liang WH, Zhao Y, et al., Comorbidity and its impact on 1590 patients with Covid-19 in China: A Nationwide Analysis. Eur Respir J, 2020. Mar 26. pii: 2000547.

doi: 10.1183/13993003.00547-2020.

23. Guan W, Ni Z, Hu Y, et al., Clinical Characteristics of Coronavirus Disease 2019 in China. N Engl J Med, 2020. 382(18): p. 1708-1720.

24. Liu J, Liu Y, Xiang P, et al., Neutrophil-to-lymphocyte ratio predicts severe illness patients with 2019 novel coronavirus in the early stage. MedRxiv, 2020.doi: https://doi.org/10.1101/2020.02.10.20021584

25. Zhang JJ, Dong X, Cao YY, et al., Clinical characteristics of 140 patients infected with SARS-CoV-2 in Wuhan, China. Allergy, 2020. Feb 19. doi: 10.1111/all.14238.

26. Fu L, Wang B, Yuan T, et al., Clinical characteristics of coronavirus disease 2019 (COVID-19) in China: A systematic review and meta-analysis. J Infect, 2020. pii: S0163-4453(20)30170-5. doi: 10.1016/j.jinf.2020.03.041.

27. Rodriguez-Morales AJ, Cardona-Ospina JA, Gutiérrez-Ocampo E et al., Clinical, laboratory and imaging features of COVID-19: A systematic review and meta-analysis. Travel Med Infect Dis, 2020: p. 101623.

28. de Groot RJ, Baker SC, Baric RS et al., Middle East respiratory syndrome coronavirus (MERS-CoV): announcement of the Coronavirus Study Group. J Virol, 2013. 87(14): p. 7790-2.

29. Yin Y \& Wunderink RG, MERS, SARS and other coronaviruses as causes of pneumonia. Respirology, 2018. 23(2): p. 130-137.

\section{Tables}

Table 1 Basic characteristics of included studies in the meta-analysis and estimating prevalence of several symptoms related to novel coronavirus (COVID-19) patients 


\begin{tabular}{|c|c|c|c|c|c|c|c|c|c|}
\hline \multirow{2}{*}{$\begin{array}{c}\text { First } \\
\text { author } \\
\text { (year) }\end{array}$} & \multirow{2}{*}{$\begin{array}{c}\text { Sample } \\
\text { size } \\
(\mathrm{n}) \\
\end{array}$} & \multirow{2}{*}{$\begin{array}{c}\text { Male } \\
\text { (n) }\end{array}$} & \multirow{2}{*}{$\begin{array}{c}\text { Median } \\
\text { age } \\
\text { (years) }\end{array}$} & \multirow{2}{*}{$\begin{array}{l}\text { Severe } \\
\text { patients } \\
\text { (n) } \%\end{array}$} & \multicolumn{5}{|c|}{ Symptoms } \\
\hline & & & & & $\begin{array}{l}\text { Fever } \\
(\%)\end{array}$ & $\begin{array}{l}\text { Cough } \\
(\%)\end{array}$ & $\begin{array}{c}\text { Myalgia } \\
\text { or Fatigue } \\
(\%)\end{array}$ & $\begin{array}{c}\text { Dyspnoea } \\
(\%)\end{array}$ & $\begin{array}{l}\text { Headache } \\
\text { (\%) }\end{array}$ \\
\hline $\begin{array}{l}\text { C. Huang } \\
\text { et al. } \\
\text { (2020) [6] }\end{array}$ & 41 & 30 & 49 & 13 (31\%) & 97.56 & 75.61 & $\begin{array}{c}(\%) \\
43.90\end{array}$ & 53.66 & 7.32 \\
\hline $\begin{array}{l}\text { D. Wang } \\
\text { et al. } \\
(2020) \text { [8] }\end{array}$ & 138 & 75 & 56 & 36 (26\%) & 98.55 & 59.42 & 69.57 & 31.16 & 6.52 \\
\hline $\begin{array}{l}\text { W. Guan } \\
\text { et al. } \\
(2020) \text { [2 } \\
3]\end{array}$ & 1,099 & 640 & 47 & $173(16 \%)$ & 88.72 & 67.79 & 38.13 & 18.65 & 13.65 \\
\hline $\begin{array}{l}\text { J. Zhang } \\
\text { et al. } \\
(2020) \text { [2 } \\
5]\end{array}$ & 140 & 71 & 57 & $58(41 \%)$ & 78.57 & 64.29 & 64.29 & 31.43 & $\mathrm{NA}$ \\
\hline $\begin{array}{l}\text { WJ. Guan } \\
\text { et al. } \\
(2020) \text { [2 } \\
\text { 2] }\end{array}$ & 1,590 & 904 & 49 & $254(16 \%)$ & 84.97 & 66.16 & 36.73 & 20.82 & 12.89 \\
\hline $\begin{array}{l}\text { J. Liu et } \\
\text { al. } \\
(2020)[2 \\
4]\end{array}$ & 61 & 31 & 40 & $17(28 \%)$ & 98.36 & 63.93 & 57.38 & 16.39 & 34.43 \\
\hline $\begin{array}{l}\text { N. Chen } \\
\text { et al. } \\
(2020)[2 \\
1]\end{array}$ & 99 & 67 & 56 & $23(23 \%)$ & 82.83 & 81.82 & 11.11 & 31.31 & 8.08 \\
\hline \multirow[t]{4}{*}{ Total } & 3168 & 1818 & $\begin{array}{l}\text { Median } \\
\text { age }=49 \\
\text { years }\end{array}$ & 574 & - & - & - & - & - \\
\hline & \multicolumn{4}{|c|}{$\begin{array}{c}\text { Overall Prevalence } \\
(95 \% \mathrm{CI})\end{array}$} & $\begin{array}{l}87.89 \\
(83.22, \\
91.39)\end{array}$ & $\begin{array}{l}68.23 \\
(63.52 \\
70.74)\end{array}$ & $\begin{array}{l}45.04 \\
(32.29, \\
55.18)\end{array}$ & $\begin{array}{l}27.03 \\
(21.52, \\
33.34)\end{array}$ & $\begin{array}{l}13.08 \\
(9.52, \\
17.72)\end{array}$ \\
\hline & \multirow{2}{*}{\multicolumn{4}{|c|}{ for heterogeneity }} & 83 & 62 & 95 & 88 & 83 \\
\hline & & & & & & & & & \\
\hline
\end{tabular}

Note: Meta-analysis for the prevalence was calculated from binary random-effects model analysis (see, Figure 1 for details).

\section{Figures}




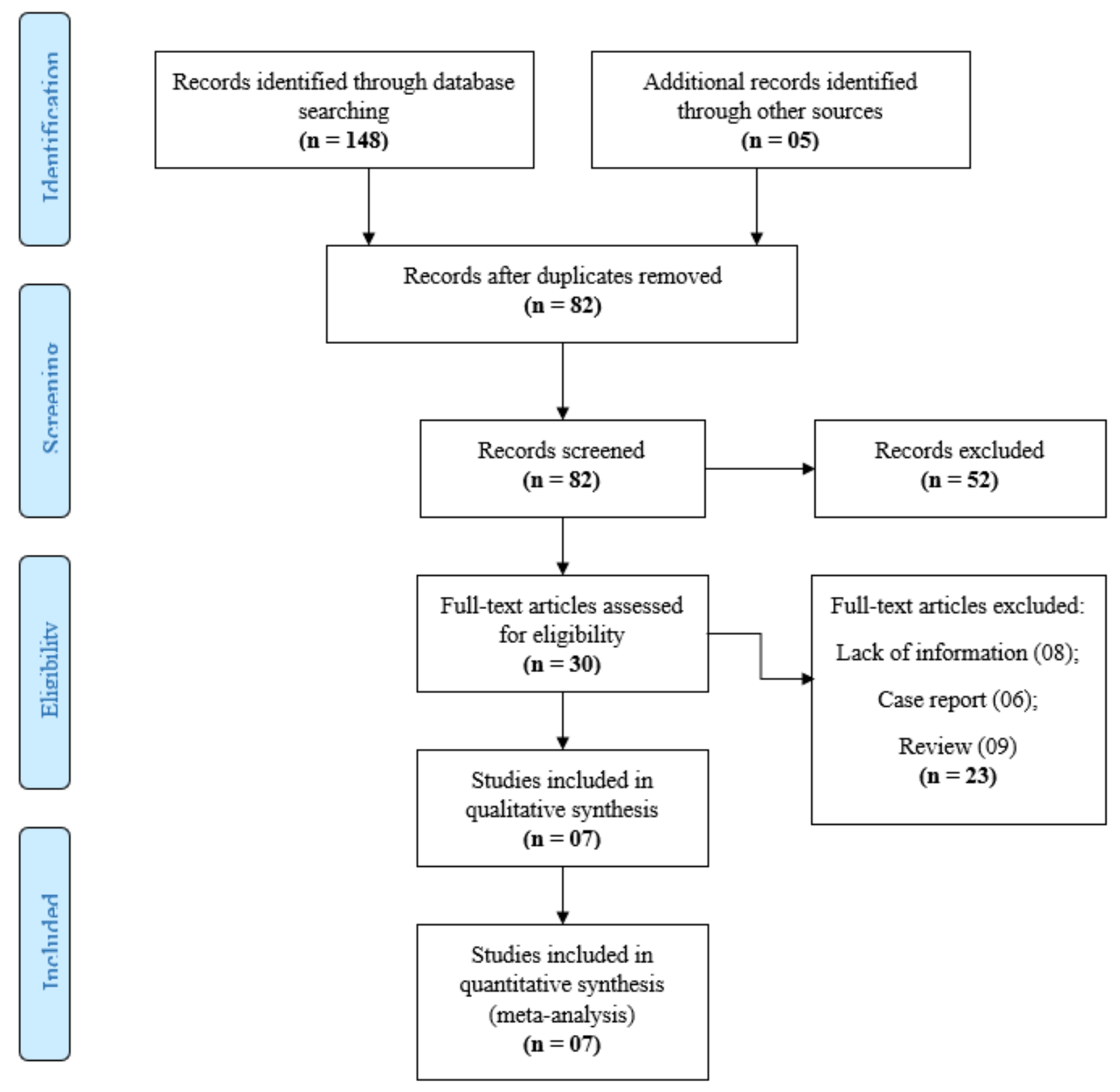

Figure 1

Flow diagram of literature search for including studies in meta-analysis 


\section{A. Fever}

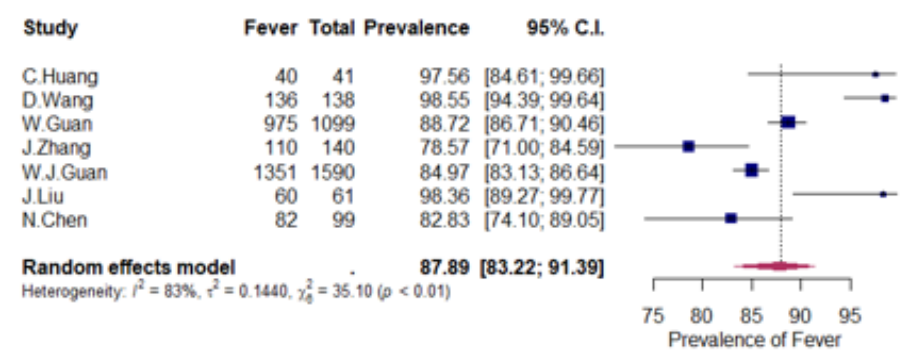

\section{Myalgia or Fatigue}

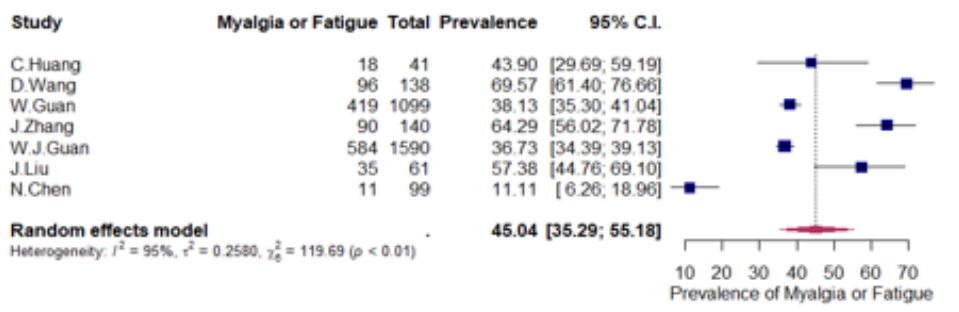

\section{B. Cough}

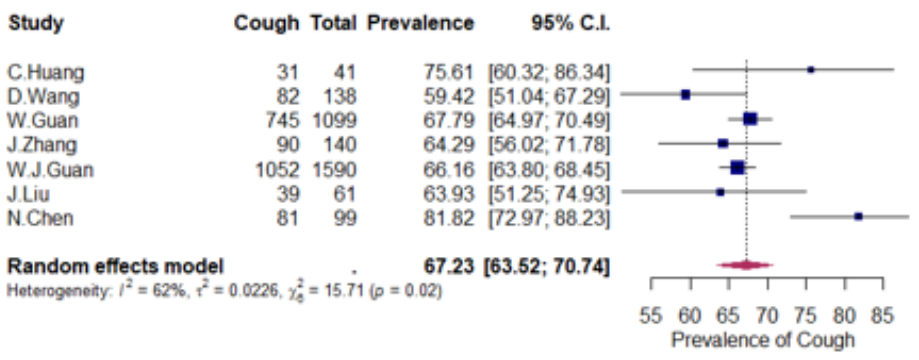

\section{Dyspnoea}

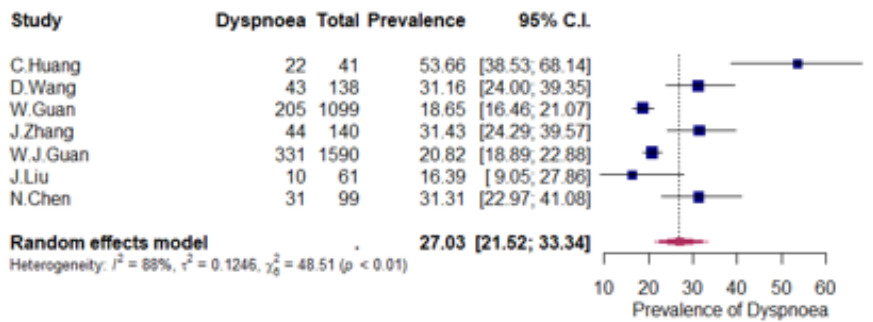

\section{E. Headache}

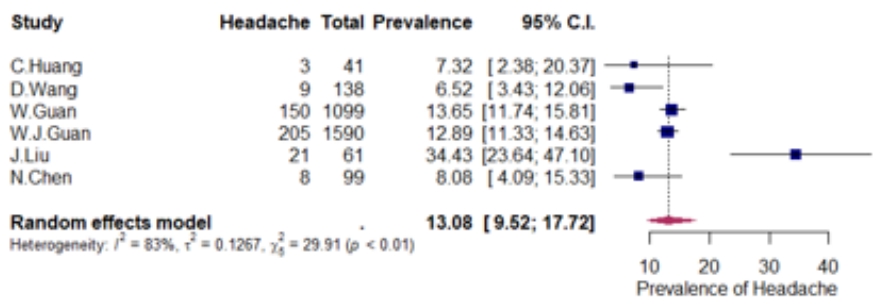

\section{Figure 2}

Meta-Analysis of symptoms of COVID-19. A, B, C, D \& E represents the prevalence of Fever, Cough, Myalgia or Fatigue, Dyspnoea \& Headache, respectively. 


\section{A. Fever}

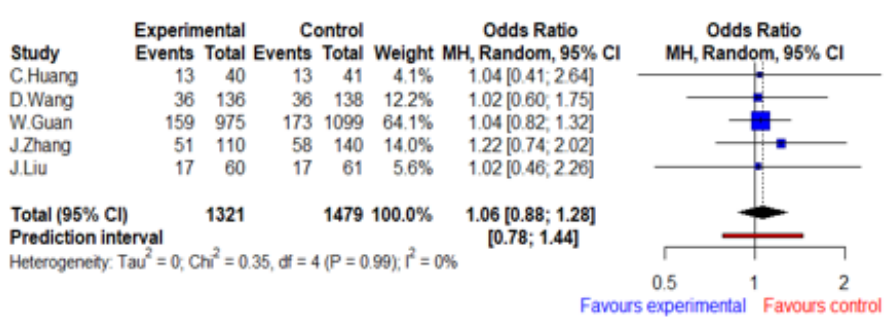

\section{Myalgia or Fatigue}

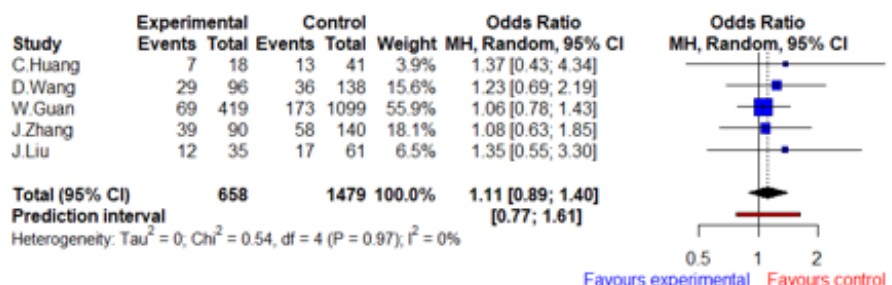

\section{B. Cough}

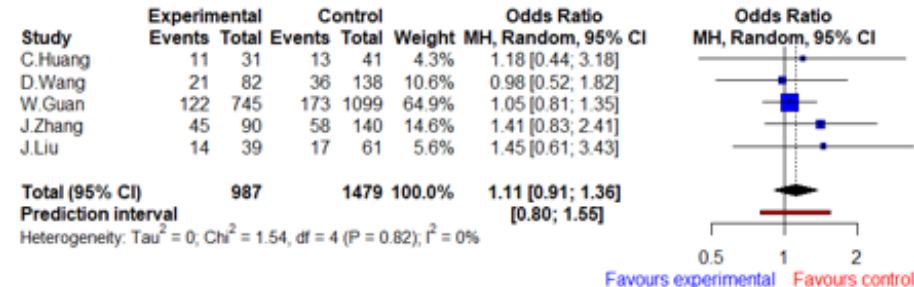

\section{Dyspnoea}

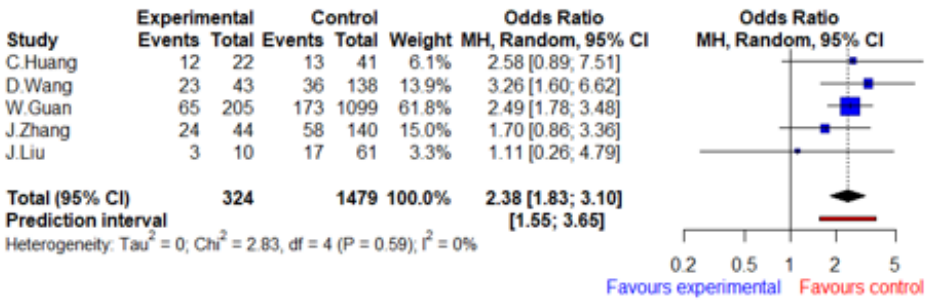

\section{E. Headache}

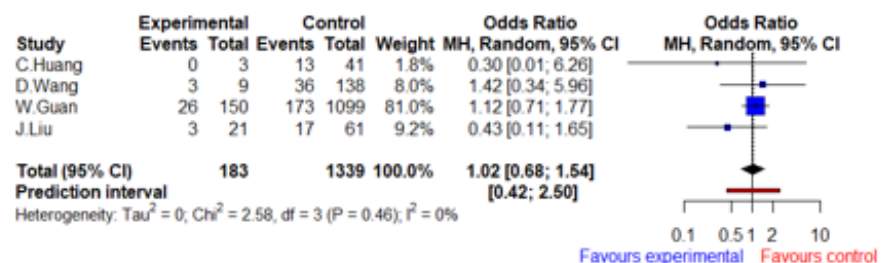

\section{Figure 3}

Meta-Analysis representing severity of symptoms in COVID-19 patients. A, B, C, D \& E represents Mantel-Haenszel $(\mathrm{MH})$ odds ratio of Fever, Cough, Myalgia or Fatigue, Dyspnoea \& Headache, respectively. Note: In all figures, "Experimental Events" represents the no. of severe patients having corresponding symptom; "Control Events" represents all the severe patients reporting in the particular study. 
A. Fever

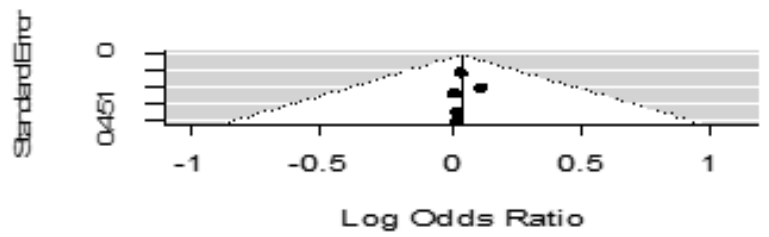

$P$ value of Egger's test $=0.985$

C. Myalgia or Fatigue

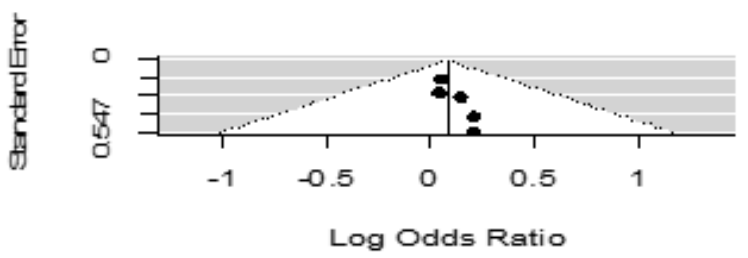

$P$ value of Egger's test $=0.051$
B. Cough

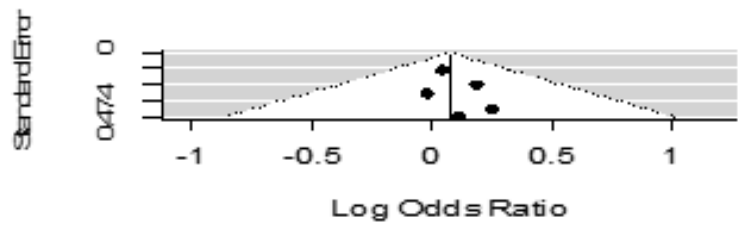

$P$ value of Egger's test $=\mathbf{0 . 3 8 6}$

D. Dyspnoea

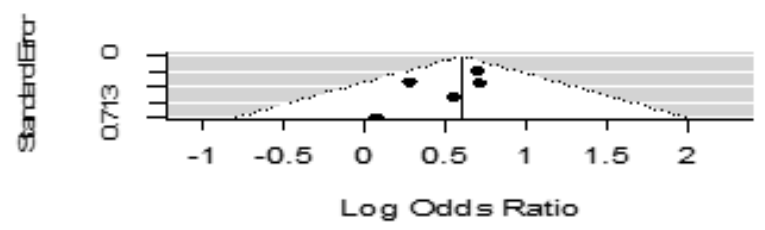

$P$ value of Egger's test $=0.251$

\section{E. Headache}
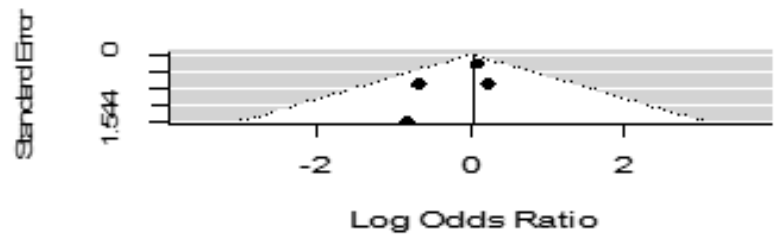

$P$ value of Egger's test $=0.359$

Figure 4

Funnel plot with Egger's test for assessing publication bias. (A) Fever; (B) Cough; (C) Myalgia or Fatigue; (D) Dyspnoea; (E) Headache.

\section{Supplementary Files}

This is a list of supplementary files associated with this preprint. Click to download.

- SupplementaryTable.docx 


\section{University Library}

\section{- M M N E R VA A gateway to Melbourne's research publications}

Minerva Access is the Institutional Repository of The University of Melbourne

Author/s:

Talukder, A;Razu, SR;Alif, S;Rahman, MA;Islam, SMS

Title:

Association between symptoms and severity of disease in hospitalised novel coronavirus (COVID-19) patients: A systemic review and meta-analysis

Date:

2020

\section{Citation:}

Talukder, A., Razu, S. R., Alif, S., Rahman, M. A. \& Islam, S. M. S. (2020). Association between symptoms and severity of disease in hospitalised novel coronavirus (COVID-19) patients: A systemic review and meta-analysis. Research Square, https://doi.org/10.21203/ rs.3.rs-31795/v1.

Persistent Link:

http://hdl.handle.net/11343/278503

License:

CC BY 